\title{
Human-Biomonitoring derived exposure and Daily Intakes of Bisphenol A and their associations with neurodevelopmental outcomes among children of the Polish Mother and Child Cohort Study
}

Mercè Gari ${ }^{\prime *}$ (i), Rebecca Moos², Daniel Bury², Monika Kasper-Sonnenberg ${ }^{2}$, Agnieszka Jankowska $^{3}$, Aleksandra Andysz ${ }^{4}$, Wojciech Hanke ${ }^{5}$, Dennis Nowak ${ }^{6}$, Stephan Bose-O'Reilly ${ }^{6}$, Holger M. Koch ${ }^{2}$ and Kinga Polanska ${ }^{3}$

\begin{abstract}
Background: Bisphenol A (BPA) is an industrial chemical mostly used in the manufacture of plastics, resins and thermal paper. Several studies have reported adverse health effects with BPA exposures, namely metabolic disorders and altered neurodevelopment in children, among others. The aim of this study was to explore BPA exposure, its socio-demographic and life-style related determinants, and its association with neurodevelopmental outcomes in early school age children from Poland.

Methods: A total of 250 urine samples of 7 year-old children from the Polish Mother and Child Cohort Study (REPRO_PL) were analyzed for BPA concentrations using high performance liquid chromatography with online sample clean-up coupled to tandem mass spectrometry (online-SPE-LC-MS/MS). Socio-demographic and lifestylerelated data was collected by questionnaires or additional biomarker measurements. Emotional and behavioral symptoms in children were assessed using mother-reported Strengths and Difficulties Questionnaire (SDQ). Cognitive and psychomotor development was evaluated by Polish adaptation of the Intelligence and Development Scales (IDS) performed by trained psychologists.

Results: Urinary BPA concentrations and back-calculated daily intakes (medians of $1.8 \mu \mathrm{g} / \mathrm{l}$ and $46.3 \mathrm{ng} / \mathrm{kg} \mathrm{bw} /$ day, respectively) were similar to other European studies. Urinary cotinine levels and body mass index, together with maternal educational level and socio-economic status, were the main determinants of BPA levels in Polish children. After adjusting for confounding factors, BPA has been found to be positively associated with emotional symptoms ( $\beta$ : $0.14,95 \% \mathrm{Cl}$ : 0.022; 0.27). Cognitive and psychomotor development were not found to be related to BPA levels.
\end{abstract}

\footnotetext{
* Correspondence: merce.gari@helmholtz-muenchen.de

Institute and Clinic for Occupational, Social and Environmental Medicine,

University Hospital, LMU Munich. Institute of Computational Biology,

Helmholtz Zentrum München, Munich, Germany

Full list of author information is available at the end of the article
}

(c) The Author(s). 2021, corrected publication 2023 Open Access This article is licensed under a Creative Commons Attribution 4.0 International License, which permits use, sharing, adaptation, distribution and reproduction in any medium or format, as long as you give appropriate credit to the original author(s) and the source, provide a link to the Creative Commons licence, and indicate if changes were made. The images or other third party material in this article are included in the article's Creative Commons licence, unless indicated otherwise in a credit line to the material. If material is not included in the article's Creative Commons licence and your intended use is not permitted by statutory regulation or exceeds the permitted use, you will need to obtain permission directly from the copyright holder. To view a copy of this licence, visit http://creativecommons.org/licenses/by/4.0/. The Creative Commons Public Domain Dedication waiver (http://creativecommons.org/publicdomain/zero/1.0/) applies to the data made available in this article, unless otherwise stated in a credit line to the data. 
Conclusions: This study represents the first report of BPA levels and their determinants in school age children in Poland. The exposure level was found to be related to child emotional condition, which can have long-term consequences including social functioning and scholastic achievements. Further monitoring of this population in terms of overall chemical exposure is required.

Keywords: Birth cohort, Bisphenol A, Children, Daily Intake, Neurodevelopment, Poland

\section{Background}

Bisphenol A (BPA) is an organic compound mostly used in the manufacture of plastics, resins and thermal paper since the decade of the 60s [1]. There has been a widespread application of BPA in many daily use products, including food contact materials (e.g. reusable bottles, containers for beverages and food), toys, packaging, paints and water pipes, and medical devices [2]. Humans are therefore exposed to BPA through ingestion of contaminated foods and drinks, inhalation and dermal contact. Once in the human body, BPA is mainly metabolized in the liver. BPA glucuronide is the major metabolite along other minor metabolites, including BPA sulfate. The urinary elimination half-life of BPA in humans is estimated to be around $5 \mathrm{~h} \mathrm{[3].}$

Bisphenol A has been classified as toxic for human reproduction and identified as an endocrine disrupting chemical (EDC) for human health and the environment [1]. In 2019, the General Court of the EU confirmed that BPA must be listed as a "substance of very high concern" for its hormonal disrupting properties on the human body, upholding a previous decision by the European Chemicals Agency. Consequently, BPA has been already banned or restricted in the EU for some products, such as baby bottles (banned since 2011), toys (migration limit of $0.04 \mathrm{mg} / \mathrm{l})$, plastic bottles and food packaging (banned since 2018 in products for babies and children under the age of three, and for the rest, migration limit of $0.05 \mathrm{mg} / \mathrm{kg}$ ), and more recently, in thermal paper (since 2020, limit of 0.02\%) [4]. In any case, BPA is still allowed to be used in the domain of plastics all over Europe, including Poland.

As in the case of other EDCs, there is particular concern that fetuses, infants or children are more vulnerable to these exposures compared to adults [5]. BPA may interact with a variety of hormonal systems that affect growth, metabolism, and neurodevelopment. The existing studies, including several reviews, have concluded that BPA exposure might be related to neuro-behavioral problems in children [6-11]. However, the results from the existing publications are not fully consistent. The reason lies in methodological differences such as different exposure time (prenatal $v s$ infancy $v s$ childhood), exposure level, use of variety of tools for measuring neurodevelopmental domains and controlling for confounding variables. Sex-specific directions of the associations cannot be excluded either. The postulated mechanism of BPA effects, even at low doses, is complex and not fully understood. BPA interference with hormonal and genomic regulation is, however, pointed out. BPA can bind not only to nuclear and membrane estrogen receptors but also to thyroid, glucocorticoid and peroxisome proliferator-activated receptors, and it can also interact with steroidogenic enzymes [7, 9-11]. The developing brain is a key target for this compound and thus both prenatal and childhood are sensitive periods of exposure.

The worldwide prevalence of mental disorders in children and adolescents was estimated by Polanczyk et al. in a publication from 2015 [12]. The overall prevalence was reported to be $13.4 \%$ (95\% CI: $11.3-$ 15.9). Specific mental disorders such as anxiety, depressive disorders or Attention-Deficit/Hyperactivity Disorders (ADHD) had a prevalence of 6.5\% (95\% CI: $4.7-9.1), 2.6 \%$ (95\% CI $1.7-3.9$ ) and $3.4 \%$ (95\% CI 2.6-4.5), respectively [12]. These psychiatric conditions along with altered children's intellectual potential can impact children's well-being, scholastic achievement, and social functioning later in life [12].

Children may have higher BPA exposures compared to adults [13]. This can be related to developmentally appropriate differences in diet, behavior, physiology, anatomy, and toxicokinetics. In 2015, within the European framework project DEMOCOPHES, urinary BPA levels were analyzed through a harmonized protocol in mothers and children [14]. Overall, for BPA, the urinary concentrations were similar among both age groups [15]. Although only six countries were selected for the BPA assessment, the results showed few geographical differences [16]. Among the analyzed countries, Slovenia showed the highest BPA levels in children. In addition, this study showed that maximum daily BPA intakes were above the temporary tolerable daily intake (t-TDI) of $4 \mu \mathrm{g} / \mathrm{kg}$ bw/d derived by EFSA [17] in a small subset of children [16]. However, to date there are no or limited available studies on the levels of BPA in Poland, particularly for what concerns children's exposure and its health consequences. Ongoing European Human Biomonitoring Initiative (project HBM4EU, 2017-2021) give the potential for comparison of exposure levels in European countries (including Poland) based on the standard protocol [18]. 
Commercial production of BPA in Poland began in 1978, in the Southern village Kędzierzyn-Koźle. The plant was one of the first BPA process technologies in the world [19]. BPA production in Poland is about 12,000 tons/year, although another report estimated a BPA production of 20,000 tons in 2013 [19, 20]. Some Polish scientists have claimed to perform a nation-wide biomonitoring in Poland in order to evaluate the health risks posed by BPA exposure [20]. Other European countries, such as France, Sweden or Germany, have proposed to restrict the use of BPA and investigate more in depth the potential risks of this compound and other similar bisphenols in the environment [4]. The present study is therefore devoted to contribute to fill this gap by the analysis of BPA in urine samples, collected from 250 children from the Polish Mother and Child Cohort (REPRO_PL) study [21]. In addition, we aim to explore the associations of BPA levels and neurodevelopmental outcomes, following previous assessments on this cohort and other environmental exposures such as phthalates [22].

The aims of this study is to characterize the levels and socio-demographic and lifestyle-related determinants of BPA exposure in children from Poland, to calculate their estimated daily intakes, and to explore the associations with neurodevelopmental outcomes including emotional and behavioral symptoms as well as cognitive and psychomotor development.

\section{Methods}

\section{Study population and sampling}

The study is based on the Polish Mother and Child Cohort (REPRO_PL), which is described in detail in previous publications $[21,23,24]$. Briefly, the study comprised three phases covering the prenatal period (phase I: 2007-2011), child examination at the age of 1 and 2 years (phase II: 2008-2013), and child examination at the age of 7 years (phase III: 2014-2019). The REPRO_PL is aimed to assess the impact of a variety of environmental and lifestyle related factors on pregnancy outcomes and children's health. For this purpose, a sample of the Polish population was selected, sampling pregnant women (and their children) from several regions, including big cities with more than 500 thousand of inhabitants as well as small villages and towns. Out of 407 children who were followed-up until the age of 7 years, spot urine samples from 250 children (61\%) collected the day of examination (in the period 2014-15) were randomly selected for the analysis of BPA. Details of that procedure have been published previously [21, 22, 25]. Written informed consent was obtained from the parents of each child before the study, which was approved by the Ethical Committee of the Nofer Institute of Occupational Medicine, Lodz, Poland (Decision No. 22/2014).

\section{Analysis of Bisphenol A and creatinine}

Urine analyses were performed to measure concentrations of BPA as total BPA after enzymatic hydrolyses [26]. The analytical procedure has been described in detail elsewhere [27, 28]. Quality control materials (consisting of four pooled urine samples with different but known concentrations of BPA) were included in each batch of samples. The limit of quantification (LOQ, based on a signal-to-noise ratio of 9) was $0.1 \mu \mathrm{g} / \mathrm{l}$. The laboratory successfully obtained consecutive certificates for BPA analyses in urine of the external quality assessment Scheme G-Equas (www.g-equas.de) also qualified for BPA analyses within the pan-European HBM Project HBM4EU (www.HBM4EU.eu).

Urinary creatinine was determined with a working range of $0.05-5.00 \mathrm{~g}$ creatinine/ $\mathrm{l}$ by contract analysis in an accredited laboratory at the Nofer Institute of Occupational Medicine (NIOM), Lodz, Poland (Cary 60 UVVis spectrometer Agilent Technologies; MS Spektrum, Poland) [29].

\section{Socio-demographic and lifestyle-related variables}

The following socio-demographic information was obtained by questionnaire filled out by mothers at child examination: place of residence (rural, urban; defined using a threshold of 10 thousand of inhabitants); household status (single parenthood, parents living together); number of siblings (none, 1, 2 or more); socio-economic status (SES) of the family (least affluent, affluent and most affluent; defined using a subjective assessment of the mothers with four possible answers: very poor or poor, good and very good, respectively); parental educational level (years of completed education: $\leq 9,10-12$, > 12); parental occupational activity (yes, no); child sex and age (exact age based on date of examination and date of birth). Parental age was calculated for date at child birth. Data concerning breastfeeding (no: $<2$ weeks, short: 2 weeks -6 months, long: $>6$ months) was collected after delivery and at follow-up examinations. Information on children's passive smoking at the age of 7 years was extracted from cotinine levels in urine analysed by LC-ESI-MS/MS method in an accredited laboratory at NIOM [30, 31] (LOQ was $0.7 \mu \mathrm{g} / \mathrm{l}$ ). A cut-off value of $2.1 \mu \mathrm{g} / \mathrm{l}$ for child environmental tobacco smoke exposure (ETS) was selected based on the analysis that was done on the Polish children at similar age as in the current study [31]. Child height and weight were measured at the age of 7 years by trained staff based on standard protocols [21]. Body mass index (BMI) categories (underweight boys $<13.95 \mathrm{~kg} / \mathrm{m}^{2}$, girls $<13.80 \mathrm{~kg} / \mathrm{m}^{2}$; recommended weight boys $13.96-18.64 \mathrm{~kg} / \mathrm{m}^{2}$, girls 
$13.81-18.19 \mathrm{~kg} / \mathrm{m}^{2}$; overweight-obesity boys $>18.65 \mathrm{~kg} /$ $\mathrm{m}^{2}$, girls $>18.20 \mathrm{~kg} / \mathrm{m}^{2}$ ) were based on Polish reference data BMI z-scores at the age of 7 years [32]. Considering that in Poland children can start school education when they are 6 or 7 years old (which can potentially impact their exposure level and neurodevelopmental outcomes) that information was included in the models evaluating the association of BPA with neurodevelopmental outcomes. Additional variables considered in the models included mother-reported traumatic events experienced by the child (yes/no), prenatal exposure to tobacco constituents (based on cotinine levels in saliva collected from the mothers during the pregnancy period and measured by LC-ESI-MS/MS method in an accredited laboratory at NIOM, with LOQ $0.4 \mu \mathrm{g} / \mathrm{l}$ [33], and child birth weight and gestational age (based on data from medical records).

\section{Neurodevelopmental assessments}

Child emotional and behavioral symptoms were assessed by the Strengths and Difficulties Questionnaires (SDQ) (www.sdqinfo.com, parent reported) filled in by the mothers at the time as the child examination was performed [34]. The 25 items in the SDQ constitute of five scales (conduct problems, hyperactivity/inattention problems, emotional symptoms, peer relationship problems and prosocial behavior) of five items each. For each of the five scales the score ranges from 0 to 10 if all items are completed. These scores were scaled up prorata if at least 3 items were completed. All sub-scale scores excluding prosocial behavior were summed as total difficulties score (range from 0 to 40 ) to assess the total behavioral problems. Validated, scale specific cutoffs were used to classify children with the symptoms within the borderline or clinical range and within the clinical range only [34]. In addition to the five scales, two amalgamated scales, namely externalizing and internalizing scores, were calculated. Both scores range from 0 to 20. In the case of externalizing scores, conduct and hyperactivity/inattention problems are summed, while for internalizing scores, emotional symptoms and peer relationship problems are combined [35, 36].

Child cognition and psychomotor development was assessed with a Polish adaptation of the Intelligence and Development Scales (IDS) for Children aged 5-10 years, performed by trained and certified psychologists [37]. In the current study, the general intellectual ability (fluid and crystallized intelligence) as well as cognition and mathematical, language and psychomotor skills were evaluated. Reliability for fluid and crystallized intelligence equals 0.94 , and for the full scale, 0.96. A more detailed explanation on the neurodevelopmental assessments performed on the REPRO_PL children is found elsewhere [22].

\section{Daily intake and cumulative risk assessment}

Daily intake (DI) of BPA was calculated from urinary levels according to the following equation [16, 38]:

$$
\mathrm{DI}=\frac{\mathrm{BPA}_{\text {creatinine }} * \mathrm{CE}_{\text {rate }}}{\text { Fue } * \mathrm{bw}}
$$

where DI is the daily BPA intake (in $\mu \mathrm{g} / \mathrm{kg}$ bw/day); $\mathrm{BPA}_{\text {creatinine }}$ is the creatinine-adjusted BPA concentration (in $\mu \mathrm{g} \mathrm{BPA} / \mathrm{g}$ creatinine); $\mathrm{CE}_{\text {rate }}$ is the child individual body height and gender based reference values for urinary creatinine excretion rate (in g/day) [39]; Fue is the urinary excretion fraction for total BPA (sum of glucuronide, sulfate, and free BPA), assumed to be 1 [27]; and bw is the body weight for each child (in $\mathrm{kg}$ ).

\section{Data analysis}

Data analysis and graphics were performed using the statistical software R [40] and ggplot package [41]. For descriptive analysis, medians and geometric means (GM) with $95 \%$ confidence intervals (CI) of BPA were used. Percentile 95 and maximum values were also reported in the tables. Statistical differences in the covariates between children included or not included in the study were tested for significance using the Chi-square test (Supplementary Material). Two different multivariate linear regression analyses were used: on the one hand, to assess the association of socio-demographic covariates (independent variables) with BPA concentrations (dependent variable); on the other, to assess the relationship between neurodevelopmental outcomes (SDQ and IDS scores, dependent variables) with the BPA levels controlling for socio-demographic and subject characteristics (independent variables). Before inclusion in the models, BPA concentrations were transformed into the natural logarithm and standardized (centred at zero and scaled to two standard deviations) [42].

The first model (aimed to explore the associations of socio-demographic and lifestyle determinants on the levels of BPA) included the following covariates: sex, BMI, place of residence, urinary cotinine levels, SES, maternal educational level and occupational status.

For the second set of models (aimed to assess the relationships between emotional and behavioral symptoms (SDQ) and cognitive and psychomotor development of children (IDS) and BPA levels, controlling for sociodemographic characteristics) multivariate linear regression was used. In addition, other regression models were applied for SDQ: on the one hand, Poisson and negative binomial regression, and on the other, logistic regression for SDQ symptoms dichotomized (both for children within the borderline or clinical range grouped together and compared with children within normal range; and children within clinical range only compared with 
children within normal range and borderline). The SDQ models were adjusted by children's sex, age, maternal educational level, socio-economic status, household status, number of siblings, cotinine levels at age 7 and in the 1st trimester of pregnancy, and maternal age, while the IDS model were adjusted by the aforementioned variables (except age at examination, since the test is already standardized for age) in addition to the examiner. All the models underwent sensitivity analysis, including (e.g. birth weight and gestational age) or excluding (e.g. cotinine levels in pregnancy) certain variables. In addition, we explored the sex differences in the aforementioned associations by adding an interactive term between the sex and the BPA levels. The models were also checked for homoscedasticity/linearity, goodness of fit and independence of predictors using diagnostic plots, the variance inflation factor and the Jarque Bera test, respectively. The final models were selected by both AIC (Akaike Information Criteria) and BIC (Bayesian Information Criteria). Type 1 error was set to 0.05 .

\section{Results}

The characteristics of the population are described in Tables 1 and S1. Detailed description of the study population is presented in our previous publications [22, 25]. Except for age at examination $(7.2 \pm 0.23$ years $v s .7 .5 \pm$ 1.1 years; $p<0.05$ ), no differences were found between the subset of children included and not included in the BPA analysis. This analysis included almost similar proportion of boys and girls. Parental's educational level was high $(65 \%$ of the mothers and $42 \%$ of the fathers declared university degree), mostly represented in the higher SES (78 and $20 \%$ of the population indicated affluent and most affluent levels, respectively), and declared high occupational activity (89\% of the mothers and $98 \%$ of the fathers). Only $10 \%$ of the children were not breastfed (or less than 2 weeks), 32\% less than 6 months and $58 \%$ of the children longer than 6 months. About $40 \%$ of the children were exposed to ETS. Six percent of the children were classified as underweight and $17 \%$ were overweight or obese.

Neurodevelopmental outcomes, including emotional and behavioral symptoms (SDQ) and cognitive and psychomotor development (IDS) of children, are presented in Table 2 and described in detail in a precedent publication [22]. Briefly, about $25 \%$ of the children were classified within borderline/clinical range of conduct problems, emotional symptoms and hyperactivity/inattention scales (Table 2). Peer relationship problems were noted among $18 \%$ of the studied population whereas for a $7 \%$ of the children the scores for prosocial behavior scales were within borderline and clinical range. Intellectual efficiency and psychomotor skills were within the normal range.
Table 1 Characteristics of the study population (Poland, 2014$15, n=250)$

\begin{tabular}{|c|c|}
\hline & $\mathrm{N}(\%)$ \\
\hline \multicolumn{2}{|l|}{ Sex of the child } \\
\hline Female & $134(54)$ \\
\hline Male & $116(46)$ \\
\hline Child age at examination ${ }^{a}$ & $7.2 \pm 0.23$ \\
\hline \multicolumn{2}{|l|}{ BMI groups } \\
\hline Underweight & $15(6)$ \\
\hline Recommended weight & $192(77)$ \\
\hline Overweight/Obese & $43(17)$ \\
\hline \multicolumn{2}{|l|}{ Place of residence at $7 \mathrm{yr}$} \\
\hline Urban & $216(86)$ \\
\hline Rural & $34(14)$ \\
\hline \multicolumn{2}{|l|}{ Urinary cotinine levels at $7 \mathrm{yr}$} \\
\hline$<2.1 \mathrm{ng} / \mathrm{ml}$ & $148(59)$ \\
\hline$>2.1 \mathrm{ng} / \mathrm{ml}$ & $101(41)$ \\
\hline \multicolumn{2}{|l|}{ Maternal age at delivery } \\
\hline$<30$ years & $155(62)$ \\
\hline$>30$ years & $95(38)$ \\
\hline \multicolumn{2}{|c|}{ Socioeconomic status of the family at $7 \mathrm{yr}$} \\
\hline Most affluent (Very good) & $50(20)$ \\
\hline Affluent (Good) & $195(78)$ \\
\hline Least affluent (Poor or very poor) & $5(2)$ \\
\hline \multicolumn{2}{|l|}{$\begin{array}{l}\text { Maternal educational level at } 7 \mathrm{yr} \\
\text { (years of completed education) }\end{array}$} \\
\hline$\leq 9$ & $5(2)$ \\
\hline $10-12$ & $83(33)$ \\
\hline$>12$ & $162(65)$ \\
\hline \multicolumn{2}{|l|}{ Maternal occupational status at $7 \mathrm{yr}$} \\
\hline No & $28(11)$ \\
\hline Yes & $219(89)$ \\
\hline
\end{tabular}

${ }^{\mathrm{a}}$ Mean $\pm \mathrm{SD}$

Urinary BPA was determined in all of the studied 7year old children from the Polish REPRO_PL cohort $(n=250)$, with BPA below the LOQ in only one sample. The concentrations ranged between <LOQ (treated as $\mathrm{LOQ} / 2$, i.e. $0.05 \mu \mathrm{g} / \mathrm{l}$ ) and $53.1 \mu \mathrm{g} / \mathrm{l}$, with a median of $1.8 \mu \mathrm{g} / \mathrm{l}(\mathrm{GM}$ of $1.9 \mu \mathrm{g} / \mathrm{l})$ and a 95th percentile of $10.7 \mu \mathrm{g} / \mathrm{l}$ (Table 3). Creatinine-adjusted concentrations ranged between $0.081 \mu \mathrm{g} / \mathrm{g}$ creatinine and $92.5 \mu \mathrm{g} / \mathrm{g}$ creatinine, with a median level of $2.6 \mu \mathrm{g} / \mathrm{g}$ creatinine (Table 3). Table 4 shows an international comparison of urinary BPA levels reported from different studies.

Figure 1 shows the univariate associations of several socio-demographic and lifestyle-related determinants on the levels of BPA in studied children. Specifically, BPA concentrations were higher among children exposed to ETS (Fig. 1). Maternal educational level and SES were 
Table 2 Child neurodevelopmental scores for behavioral problems (SDQ) and cognitive and psychomotor development (IDS) in children from Poland $(n=250)$

\begin{tabular}{llll}
\hline Neurodevelopmental outcomes & Mean ( \pm SD) & Range & Borderline/Clinical (\%) \\
\hline Behavioral scales (SDQ) & & $4-10$ & 7 \\
Prosocial behavior & $8( \pm 2)$ & $0-7$ & 28 \\
Conduct problems & $2( \pm 1)$ & $0-8$ & 25 \\
Emotional Symptoms & $2( \pm 2)$ & $0-10$ & 24 \\
Hyperactivity/Inattention problems & $4( \pm 3)$ & $0-7$ & 18 \\
Peer relationship problems & $1( \pm 2)$ & $0-26$ & 19 \\
Total difficulties & $9( \pm 5)$ & $0-13$ & $\mathrm{NA}$ \\
Internalizing scores & $4( \pm 3)$ & $0-15$ & $\mathrm{NA}$ \\
Externalizing scores & $6( \pm 3)$ & & $\mathrm{NA}$ \\
Intellectual ability (IDS) & & $56-136$ & $\mathrm{NA}$ \\
Fluid intelligence (IQ) & $104( \pm 14)$ & $60-142$ & $\mathrm{NA}$ \\
Crystallized intelligence (IQ) & $104( \pm 15)$ & $17-99$ & $\mathrm{NA}$ \\
Cognition & $73( \pm 12)$ & $3-19$ & $\mathrm{NA}$ \\
Mathematical skills & $11( \pm 3)$ & $11-43$ & $\mathrm{NA}$ \\
Motor skills & $30( \pm 6)$ & $6-32$ & \\
Language skills & $21( \pm 5)$ & &
\end{tabular}

inversely associated to BPA concentrations in children, with highest BPA levels among children whose mothers had low educational levels or those belonging to the least affluent socio-economic status (Fig. 1). The concentrations of BPA were significantly lower ( $p$-value $<0.05$, Fig. 1) in children with underweight. Figure 2 shows a more detailed distribution of the BPA levels by z-score BMI groups. Specifically, BPA concentrations are widespread within children in the healthy weight group. Children classified as overweighted and obese usually ranged in the highest BPA levels, while BPA in underweighted children was within the low range (Fig. 2). Creatinineadjusted BPA concentrations for each BMI group are found in Table S2 (Supporting Information). Other sociodemographic determinants, such as children's sex, number of siblings, place of residence or maternal age did not show any significant difference with the levels of BPA (Fig. 1). Multivariate regression models confirmed some of the aforementioned trends (Fig. S1). Specifically, children whose urinary cotinine levels were higher than
$2.1 \mathrm{ng} / \mathrm{ml}$ showed higher BPA levels, and also underweight was inversely related to BPA concentrations, being both variables statistically significant at a $10 \%$ confidence level (p-value < 0.1; Fig. S1).

Figures 3 and 4 show the results for the association of BPA exposure with children's a) emotional and behavioral outcomes and b) intelligence, cognition, mathematical, language and psychomotor skills considered as continuous variables (SDQ and IDS, respectively). After controlling for sociodemographic and lifestyle-related factors, BPA was found to be positively associated with emotional symptoms ( $\beta$ : $0.14,95 \%$ CI: $0.021 ; 0.27)$. The other scales, namely conduct problems, hyperactivity/inattention problems and peer relationships problems, together with the prosocial behavior, as well as the total difficulties score, were not found to be significantly associated with the BPA concentrations in 7-year old children (Fig. 3). When the symptoms were dichotomized (within borderline/clinical range vs. normal range or clinical range vs. normal/borderline range) the observed

Table 3 BPA urinary concentrations (in $\mu \mathrm{g} / \mathrm{l}$ and $\mu \mathrm{g} / \mathrm{g}$ creatinine) and daily intakes (in $\mathrm{ng} / \mathrm{kg}$ bw/day) in children from Poland (REPRO_PL birth cohort, $\mathrm{n}=250$ )

\begin{tabular}{|c|c|c|c|c|c|c|}
\hline & $\mathrm{GM}^{\mathrm{a}}\left(95 \% \mathrm{Cl}^{\mathrm{b}}\right)$ & Median & $\mathrm{P} 25^{\mathrm{c}}$ & $P 75^{d}$ & $\mathrm{P} 95^{\mathrm{e}}$ & Range \\
\hline $\begin{array}{l}\text { Urinary BPA concentrations } \\
(\mu g / l)\end{array}$ & $1.9(1.7-2.1)$ & 1.8 & 1.1 & 2.8 & 10.7 & $0.05-53.1$ \\
\hline $\begin{array}{l}\text { Urinary BPA concentrations } \\
\text { ( } \mu \mathrm{g} / \mathrm{g} \text { creatinine) }\end{array}$ & $2.8(2.5-3.1)$ & 2.6 & 1.7 & 4.0 & 16.3 & $0.081-92.5$ \\
\hline $\begin{array}{l}\text { Daily Intakes of BPA } \\
(n g / k g \text { bw/day) }\end{array}$ & $50.0(44.5-56.1)$ & 46.3 & 28.8 & 75.9 & 301.7 & $1.6-1840$ \\
\hline
\end{tabular}


Table 4 Comparison of BPA concentrations in different children populations worldwide

\begin{tabular}{|c|c|c|c|c|c|}
\hline Location & Year & $n$ & Age & $\mathrm{BPA}(\mu \mathrm{g} / \mathrm{l})^{\mathrm{a}}$ & Reference \\
\hline Poland & 2014-15 & 250 & 7 & $1.9[1.7-2.1]$ & This study \\
\hline Europe & $2011-12$ & 653 & $5-12$ & $2.0[1.8-2.2]$ & [16] \\
\hline Germany & $2006-2010$ & 465 & $8-10$ & $2.2[2.0-2.4]$ & {$[43]$} \\
\hline Portugal & 2014-15 & 110 & $4-18$ & $1.6[1.2-2.1]$ & [44] \\
\hline Denmark & 2011 & 143 & $6-11$ & $1.7[1.1-3.7]^{\mathrm{b}}$ & {$[45]$} \\
\hline Norway & 2012 & 56 & $6-12$ & $3.1[1.8-4.1]^{\mathrm{b}}$ & {$[46]$} \\
\hline Slovenia & 2011-12 & 145 & $6-11$ & $2.4[0.67-4.6]^{\mathrm{b}}$ & [47] \\
\hline Turkey & 2015-16 & 125 & $3-6$ & $0.60^{\mathrm{b}}$ & [48] \\
\hline US & 2013-14 & 409 & $6-11$ & $1.4[1.3-1.6]$ & [49] \\
\hline Ohio, US & 2003-14 & 222 & 8 & $1.6[1.0-3.6]^{\mathrm{b}}$ & {$[50]$} \\
\hline Canada & 2013-16 & 77 & $3-4$ & $1.0[0.6-1.5]$ & [51] \\
\hline Brazil & 2012-13 & 300 & $6-14$ & $1.7[0.30-35.9]^{\mathrm{c}}$ & [52] \\
\hline China & 2009-10 & 412 & 7 & $2.7[2.2-3.2]$ & [53] \\
\hline Hong Kong & 2016 & 31 & $4-6$ & $1.7[0.72-2.3]^{b}$ & {$[54]$} \\
\hline South Korea & 2016 & 162 & 7-9 & $0.60[0.34-1.2]^{\mathrm{b}}$ & {$[55]$} \\
\hline India & $2012-13$ & 76 & $2-14$ & $5.1[0.070-41.4]^{c}$ & {$[56]$} \\
\hline
\end{tabular}

effect estimates on the emotional symptoms were not maintained (Fig. S4). Cognitive and psychomotor development measured with IDS were not found to be associated with BPA levels after controlling for covariates. The results did not change in the sensitivity analyses with inclusion or exclusion of certain variables (Figs. S5 and S7 for SDQ and IDS, respectively). On the other hand, different effects depending on the children's sex were not found. This was assessed using an interactive term between sex and BPA levels on the associations with neurodevelopmental outcomes (data not shown).

\section{Discussion}

In general, the BPA concentrations in Poland $(1.9 \mu \mathrm{g} / \mathrm{l})$ ranged within similar levels as those found in other European school-age children (Table 4). For 653 European children (DEMOCOPHES study) a median level of $2.0 \mu \mathrm{g} / \mathrm{l}$ was reported, with some differences among European member states [16]. For instance, Slovenia and Belgium were the two countries with the highest BPA levels $(2.6 \mu \mathrm{g} / \mathrm{l}$ and $2.4 \mu \mathrm{g} / \mathrm{l}$, respectively), in comparison to the other European locations analyzed in the report, such as Denmark, Spain, Luxembourg and Sweden (ranging from $1.5 \mu \mathrm{g} / \mathrm{l}$ to $1.9 \mu \mathrm{g} / \mathrm{l}$ ) [16]. Other European studies performed in Portugal $(1.6 \mu \mathrm{g} / \mathrm{l})$, Denmark $(1.7 \mu \mathrm{g} / \mathrm{l})$, Slovenia $(2.4 \mu \mathrm{g} / \mathrm{l})$ and in a German cohort $(2.2 \mu \mathrm{g} / \mathrm{l})$ reported similar BPA levels [43-45, 47]. Only one study performed in 56 children aged 6-12 years from Norway reported higher BPA concentrations $(3.1 \mu \mathrm{g} / \mathrm{l})$ [46]. However, the differences regarding BPA concentrations found between those studies cannot be attributed to different population-exposure levels but to the variability in sample size, children's age, analytical procedure and sampling period. The concentrations in Poland are also in the same range than those found in US studies, including the 2013-14 NHANES report and the Ohio cohort (US), as well as in Hong Kong and Brazil, with GM concentrations ranging from $1.4 \mu \mathrm{g} / \mathrm{l}$ to $1.7 \mu \mathrm{g} / \mathrm{l}[49,52,54,57]$, but twice higher than those found in Canada, Turkey or South Korea $(0.6-1.0 \mu \mathrm{g} / \mathrm{l})$ $[48,51,55]$. The concentrations were, however, much higher in studies performed in Asian populations, such as one conducted in China $(2.7 \mu \mathrm{g} / \mathrm{l})$ and another in India $(5.1 \mu \mathrm{g} / \mathrm{l})[53,56]$.

BPA has been gradually banned in many countries since 2009, especially in food-related products for children, which has resulted in an effective decrease of BPA exposures in child populations $[58,59]$. BPA exposures in the US also declined during the time period from 2003 to 2012 [60]. Therefore different time points of sample collection, together with other relevant factors mentioned above, might contribute to the small differences in concentrations found in the reported countries and continents (Table 4) [61]. The overall trend indicates a decreasing BPA exposures among the general population.

For our study population we calculated oral daily BPA intakes using the urinary excretion fraction (Fue) for BPA. The Fue was set to a value of 1 based on human metabolism studies indicating that almost $100 \%$ of the orally administered BPA is excreted via urine within 24 $h$ after exposure [3]. In our study, the median daily BPA 

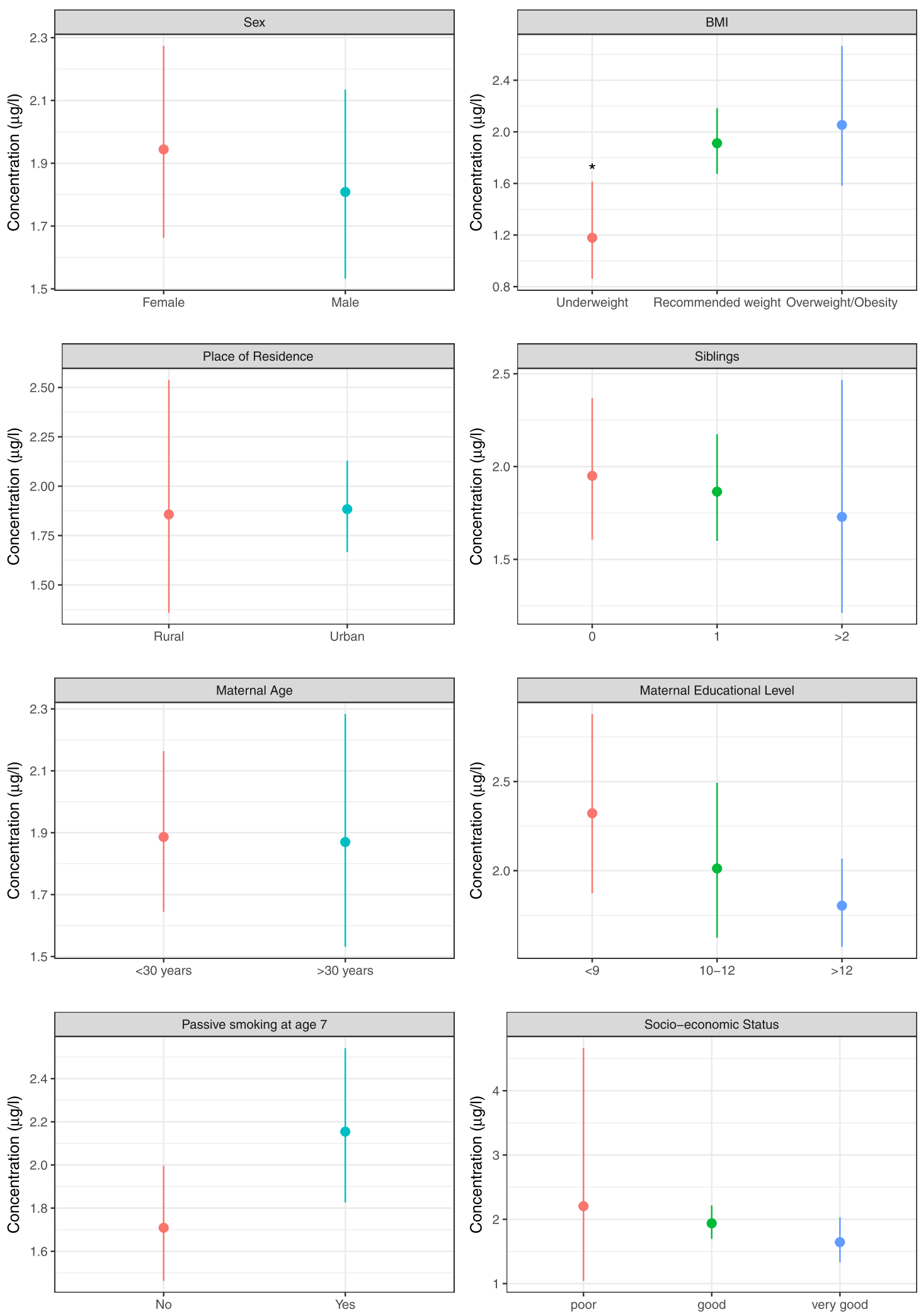

Fig. 1 Geometric means and 95\% confidence intervals $(\mu \mathrm{g} / \mathrm{l})$ of BPA concentrations in 7-year old children for several socio-demographic characteristics: children's sex and BMI, number of siblings, place of residence, passive smoking at age 7, maternal age and educational level, and socio-economic status 


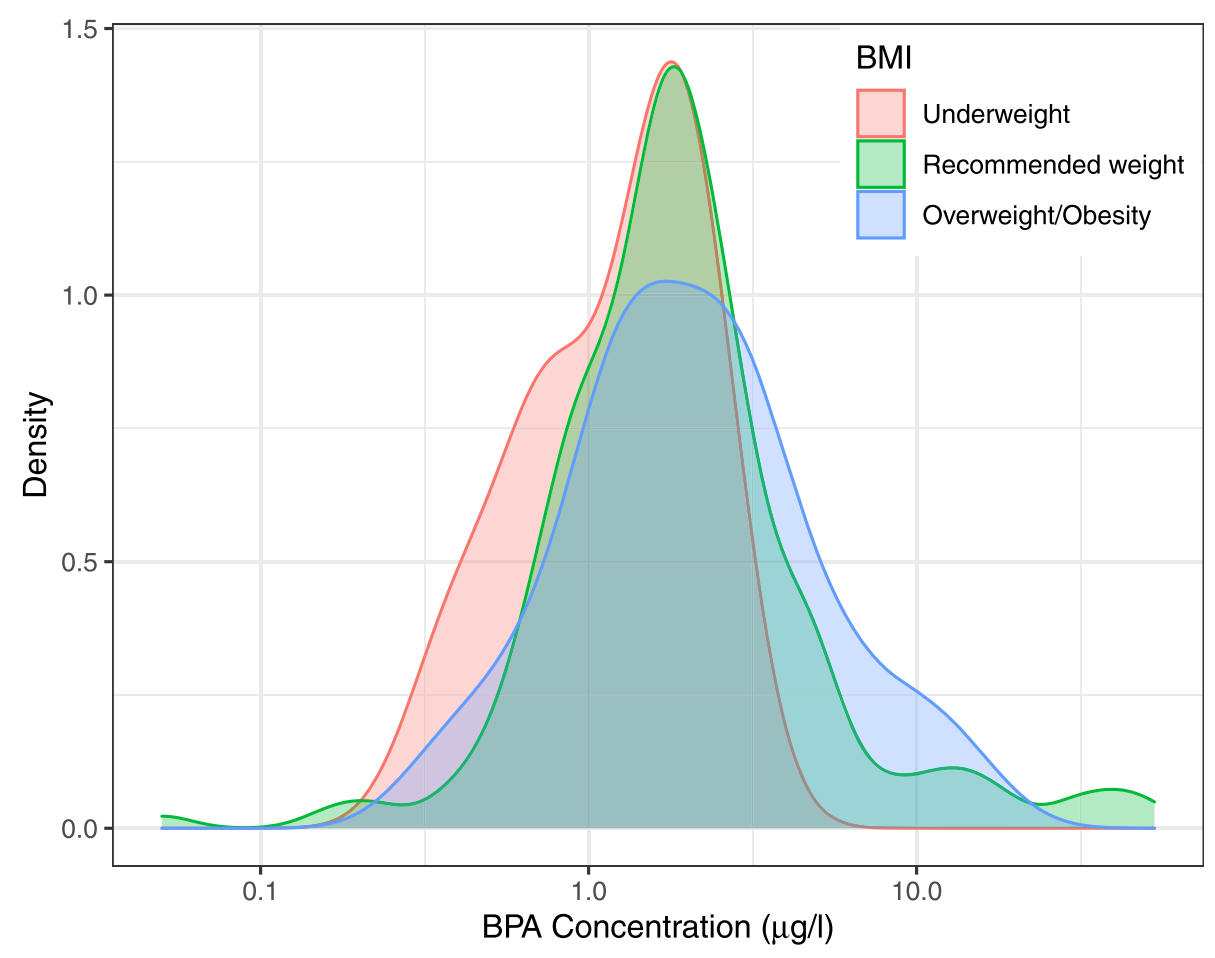

\begin{tabular}{|c|c|c|c|c|c|}
\hline BMI & GM (95\% Cl) & P25 & Median & P75 & Range \\
\hline Underweight & $1.2(0.86-1.6)$ & 0.76 & 1.4 & 1.8 & $0.36-2.5$ \\
\hline Healthy weight & $1.9(1.7-2.2)$ & 1.10 & 1.8 & 2.8 & $0.05-53$ \\
\hline Overweight/Obesity & $2.1(1.6-2.7)$ & 1.20 & 2.2 & 3.2 & $0.32-16$ \\
\hline
\end{tabular}

Fig. 2 Density plot of BPA levels for each z-score body mass index category: underweight, healthy weight, and overweight/obesity

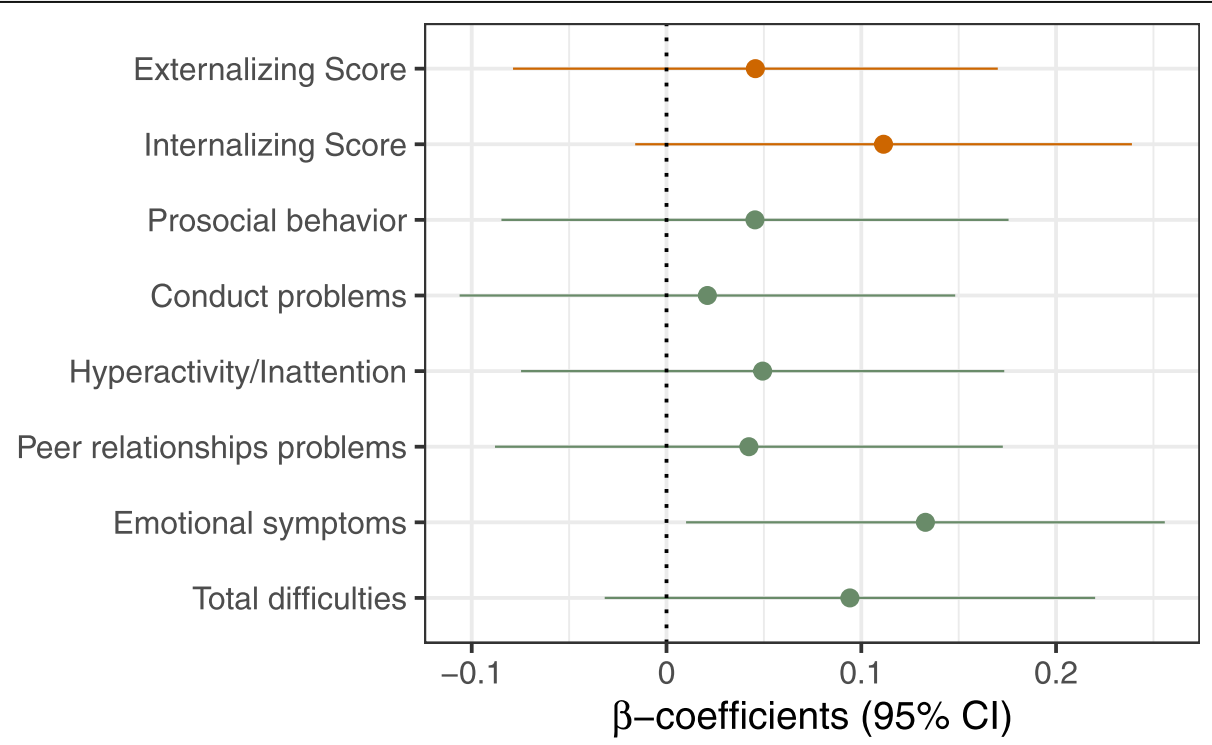

Fig. 3 Standardized beta-coefficients from multivariate regression models for BPA concentrations on the behavioral scales (SDQ) in children at 7 years of age. Models are adjusted for child's sex and age at examination, household status, SES, maternal educational level, maternal age at birth, number of siblings, cotinine levels during 1st trimester of pregnancy and in children at 7 years of age 


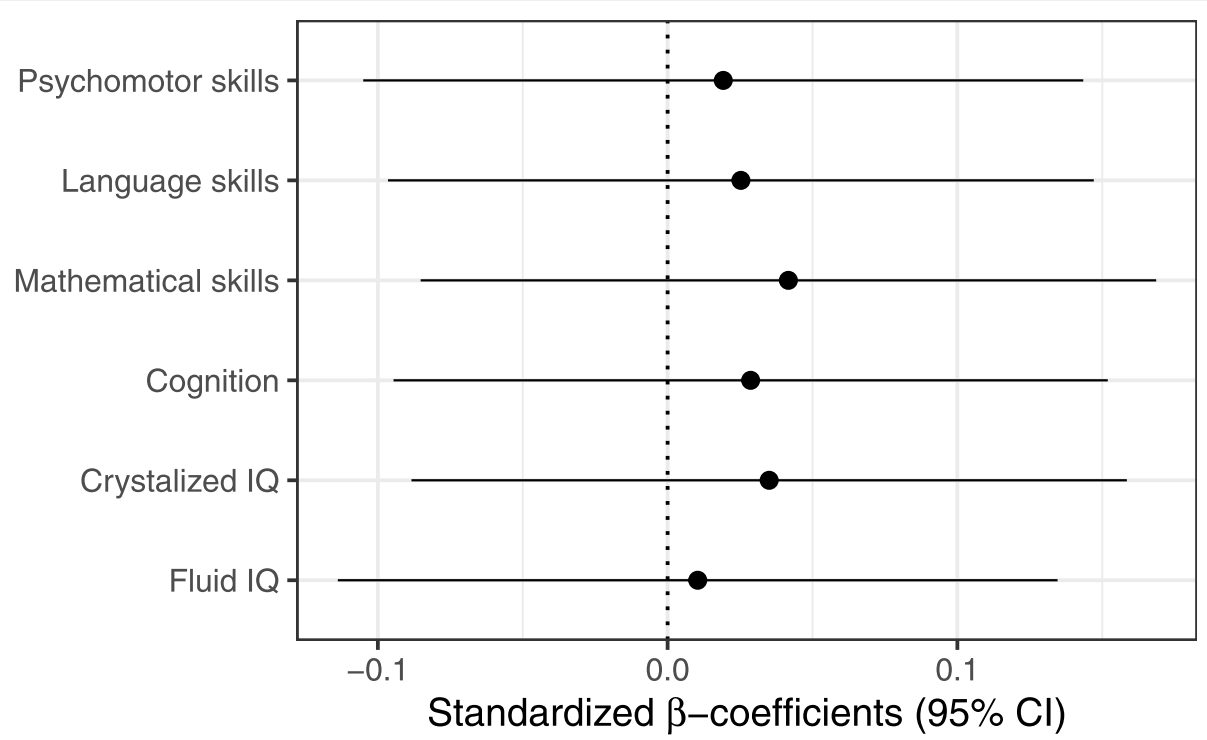

Fig. 4 Standardized beta-coefficients from multivariate regression models for BPA concentrations on intelligence and development scales (IDS) in children at 7 years of age. Models are adjusted for child's sex, examiner, household status, SES, maternal educational level, maternal age at birth, number of siblings, cotinine levels during 1st trimester of pregnancy and in children at 7 years of age

intake was $46.3 \mathrm{ng} / \mathrm{kg}$ bw/day, ranging from $1.6 \mathrm{ng} / \mathrm{kg}$ bw/day and $1840 \mathrm{ng} / \mathrm{kg}$ bw/day (Table 3). None of the studied children had BPA intakes above the European tTDI established by EFSA in 2015, set to $4 \mu \mathrm{g} / \mathrm{kg}$ bw/day [17]. Thus, the median daily intake resembled roughly $1 \%$, and the highest calculated daily intake resembled roughly $50 \%$ of this EFSA t-TDI with even bigger margins for the US EPA oral reference dose of $50 \mu \mathrm{g} / \mathrm{kg}$ bw/ day. In the worldwide context, the global BPA exposure level was estimated to be $60.1 \mathrm{ng} / \mathrm{kg}$ bw/day [62], while in Europe, children's median BPA DIs ranged from 31.3 $\mathrm{ng} / \mathrm{kg}$ bw/day to $38.2 \mathrm{ng} / \mathrm{kg}$ bw/day [16, 44, 45]. In the DEMOCOPHES study, however, the report showed DIs estimations above the t-TDI of $4 \mu \mathrm{g} / \mathrm{kg}$ bw/day in a subset of children from Denmark and Belgium [16].

Regarding educational level and socio-economic status, the European DEMOCOPHES study also found higher BPA levels among children from families with primary education in relation to secondary or tertiary education, similarly to the present results [16]. In the HOME cohort study performed in Ohio (US), the authors also found that household annual incomes and maternal education were associated with BPA levels in children, with the same trends [57]. Conversely, a recent study performed on six European cohorts found lower BPA levels in low education groups [63]. To our knowledge, none of the reports on BPA in children has found an association with sex, although a recent study performed in Turkey found higher concentrations among girls in relation to boys $[16,48]$. In relation to the body mass index, a study performed in Portuguese children found an inversed pattern, in which children with obesity had lower BPA levels than underweight/healthy weight children [44]. However, the children from this study were enrolled in a dietary program for weight loss/management, and therefore, apart from physical characteristics (e.g. BMI), diet or other determinants might influence the BPA exposure patterns in children. In fact, a recent report based on six NHANES examination cycles between 2003 and 2014 was not able to find any significant association between BPA in urine and serum lipids in children and do not hint to metabolic effects by BPA exposure [64].

In our study, BPA was found to be positively associated with emotional symptoms. What is worth emphasizing is that this result was independent of previous traumatic experiences in a child's life that is more likely expected to affect the emotional health of the children (data not shown). Even though the observed effect of BPA exposure on children emotional development is rather small, still it can have the long-term consequences looking at their social functioning and scholastic achievements. The result of the review from 2017 [8] pointed out that there is a relationship between BPA exposure both during prenatal and childhood period and negative behavioral outcomes including emotional development. However the existing studies are not fully conclusive. A study by Braun et al. (HOME cohort) assessed the effect of childhood BPA exposure on behavior and executive functions in children aged 3 years and found that the associations were largely null and not modified by child gender [65]. Harley et al. (CHAMACOS cohort) observed a relationship between BPA exposure at age 5 years and increased externalizing behaviors, including 
conduct problems, in girls at age 7 years and increased internalizing behaviors and inattention and hyperactivity behaviors in boys and girls at age 7 years [66]. Roen et al., when studying the CCCEH cohort (follow-up), showed that BPA levels in the urine of children measured at 3 and 5 years were related to the behavior of girls aged 7-9 years - higher levels of anxiety, depression and aggression were observed in them [67]. In a crosssectional study, Hong et al. showed that BPA levels in the urine of girls and boys aged 8-10 years were associated with higher levels of anxiety and depression [68]. In the Perera et al. publication (based on CCCEH cohort), childhood exposure was not significantly related to the measured anxiety and depression symptoms in children aged 10-12 years [69]. Perez-Lobato, when studying boys aged 9-11 from the INMA cohort, showed increased problems with the internalization of behavior [70]. Stacy et al. reported sex-dependent associations between BPA and child neurobehavior [50]. A 10-fold increase in 8year BPA was associated with more externalizing behaviors in boys, but not in girls [50]. Two recent studies based on data from several mother-child cohorts in Europe have also evaluated the associations between simultaneous exposure to a wide range of environmental chemicals (including BPA exposure) and child behavior $[71,72]$. BPA urinary concentrations during the prenatal period were associated with higher (worse) scores on the externalizing behavior sub-scale evaluated between 3 and 7 years of age [71] although no associations were observed for the postnatal period [72]. Discrepancies in the literature could be partly due to differences in the characteristics of the study populations (e.g. socioeconomic status) or study designs, including differences in the timing of exposure or outcome assessment, neurobehavioral assessments tools, BPA exposure misclassification, or irrelevant time frames of exposure assessment. Nevertheless, as pointed out in the existing research, BPA exposure is more frequently associated with externalizing/internalizing problems than cognitive outcomes. Both internalizing and externalizing symptoms seem to coexist and a consistent pattern in term of sexual differences is not present [11].

The future analyses should use the potential of prospective mother-child cohort study design and look more deeply at long-term consequences of BPA exposure. Thus, the continued follow-up of existing cohorts should be a priority for future studies in this area. Moreover, considering the real exposure scenario, the studies should jointly consider both vulnerable periods of exposure (prenatal and postnatal) as well as simultaneous exposures to different chemical classes. Taking into account that BPA has been classified as an endocrinedisrupting chemical, the differential effect of sex and BPA levels on neurodevelopmental outcomes should be explorer more in depth. Finally, the future research should put more efforts to focus on understanding the mechanisms that may explain the observed patterns of association, such as DNA methylation, immune dysfunction, systemic inflammation, oxidative stress, and endocrine and metabolic disruption [10]. All those above-mentioned require large sample thus an exposome-based approach considering joint analyses based on data from existing birth cohorts should be strengthen in future research.

The current study is based on a well-defined child cohort from Poland. The follow-up was performed accurately. Child mental health was assessed based on widely used standardized and validated questionnaire that distinguish children with and without emotional and behavioral symptoms. Moreover, quantitatively assessed data allows examination of the symptoms in the whole spectrum, which do often not qualify for clinical diagnosis but still might have a great impact on an individual's behavioral health and can result in long-term consequences (e.g., school achievements). In addition, child cognitive and psychomotor assessments were performed by trained and certified psychologists. IDS has a high reliability as well as high correlation with analogous WISC-R scales [73].

The laboratory analysis was performed with the highest level of internal and external quality assurance, ensuring with utmost accuracy and comparability of urinary BPA concentrations [26, 74]. We have also excluded external contamination by analyzing the conjugation status of BPA in the urine samples. Above $90 \%$ of total BPA was present in its conjugated form (data not shown). Still, we have to acknowledge that BPA is a non-persistent chemical, rapidly eliminated via urine. Exposure assessments based on a single spot of urine may thus wrongly classify the children's individual overall or long term BPA exposure. Although sex-specificity of the effects of BPA and child neurodevelopment has been underlined in existing studies, we were not able to find such association, probably due to the available sample size. On the statistical side, although the models were validated and underwent sensitivity analysis, since they were adjusted for numerous variables, the possibility of residual or unmeasured confounding cannot be excluded. In addition, other chemical exposures such as phthalates (which were measured in a previous study [25]) were not considered in the current analysis. Finally, causality cannot be inferred due to the observational nature of the current study and needs to be confirmed through the application of other methods to strengthen causal inference. Due to the cross-sectional design of this analysis, single exposure measures of BPA along with the low exposure levels are limited to capture effects of BPA on the health status during childhood. In 
addition, there is no data on previous children's exposure to BPA. Long-term exposure measures for BPA, starting with prenatal exposure estimations and repeated measures in critical developmental time frames during childhood are highly warranted to solve the problems with the short-term exposure estimations for BPA.

\section{Conclusions}

This study provides current biomonitoring data of Bisphenol A in urine of 250 children from Poland. The concentrations and daily intakes of BPA among this Polish cohort were in concordance with other European studies. Exposure with environmental tobacco smoke and body weight were associated with BPA in 7-year old children. Specifically, higher urinary cotinine concentrations were associated with higher BPA levels, and underweight children showed lower BPA levels than healthy weight or overweight/ obese children. Furhermore, this study was able to find a positive association between BPA concentrations in 7-year old children and emotional symptoms. Some neurodevelopmental problems in children might be associated to the exposure of nonpersistent chemicals such as BPA. More efforts on understanding the mechanisms that may explain the observed associations should be explored, specifically those related to gene-environment interactions.

\begin{abstract}
Abbreviations
ADHD: Attention-Deficit/Hyperactivity Disorders; AIC: Akaike Information Criteria; BIC: Bayesian Information Criteria; BMI: Body Mass Index; BPA: Bisphenol A; bw: Body weight; CE: Creatinine excretion; Cl: Confidence Interval; DI: Daily Intake; ECHA: European Chemical Association;

EDC: Endocrine disrupting chemical; EFSA: European Food Safety Authority; ETS: Environmental Tobacco Smoke; Fue: Urinary excretion fraction; GM: Geometric mean; HBM: Human Biomonitoring; IDS: Intelligence and Development Scales; LC-ESI-MS/MS: Liquid chromatography electrospray ionization tandem mass spectrometry; LOQ: Limit of quantification; MS: Mass Spectrometry; OR: Odds Ratio; REPRO_PL: Polish Mother and Child Cohort Study; SES: Socio-economic status; SDQ: Strengths and Difficulties Questionnaire; SPE-LC-MS/MS: Solid phase extraction coupled to liquid chromatography and tandem mass spectrometry; t-TDI: Temporary tolerable Daily Intake; USEPA: United States Environmental Protection Agency; WISCR: Wechsler Intelligence Scales for Children-Revised
\end{abstract}

\section{Supplementary Information}

The online version contains supplementary material available at https://doi. org/10.1186/s12940-021-00777-0.

\section{Additional file 1}

\section{Acknowledgements}

The authors would like to be grateful to the families participating in the REPRO_PL study, for their time, data and samples provided, as well as their trust. Mercè Garí acknowledges the support from the Joachim Herz Foundation through the Add-on Fellowship for Interdisciplinary Science.

\section{Authors' contributions}

MG and KP are the principal investigators of the study and wrote the main manuscript. Together with $\mathrm{WH}, \mathrm{DN}, \mathrm{SB}$ and HK , obtained the necessary funds for the study design and development. HK is responsible for the development of laboratory methods for BPA analysis, while RM and DB performed the analysis of BPA in the urine samples. AA and AJ were responsible for data acquisition and interpretation of neurodevelopmental outcomes. MG performed the statistical analyses and data visualization. HK, DB, MKS and SB provided significant contributions to the manuscript. All authors have revised the study development and approved the submitted version of the paper.

\section{Funding}

This work has received financial support from the National Science Centre, Poland, under grant No. DEC-2014/15/B/NZ7/00998; and from the Medical Faculty of the Ludwig-Maximilians-Universität Munich, Germany, under grant No. WIFOMED-80926024. MG was additionally funded by the Joachim Herz Foundation, through the Add-on Fellowship for Interdisciplinary Science. The funders had no role in study design, data collection and analysis, decision to publish, or preparation of the manuscript. Open Access funding enabled and organized by Projekt DEAL.

\section{Availability of data and materials}

The datasets used and/or analysed during the current study are available from the corresponding author on reasonable request.

\section{Declarations}

Ethics approval and consent to participate

Written informed consent was obtained from the parents of each child before the study, which was approved by the Ethical Committee of the Nofer Institute of Occupational Medicine, Lodz, Poland (Decision No. 22/ 2014)

Consent for publication

Not applicable.

\section{Competing interests}

The authors declare that they have no competing interests.

\section{Author details}

${ }^{1}$ Institute and Clinic for Occupational, Social and Environmental Medicine, University Hospital, LMU Munich. Institute of Computational Biology, Helmholtz Zentrum München, Munich, Germany. ${ }^{2}$ Institute for Prevention and Occupational Medicine of the German Social Accident Insurance, Institute of the Ruhr-University Bochum (IPA), Bochum, Germany. ${ }^{3}$ Department of Environmental and Occupational Health Hazards, Nofer Institute of Occupational Medicine (NIOM), Lodz, Poland. ${ }^{4}$ Department of Health and Work Psychology, Nofer Institute of Occupational Medicine (NIOM), Lodz, Poland. ${ }^{5}$ Department of Environmental Epidemiology, Nofer Institute of Occupational Medicine (NIOM), Lodz, Poland. ${ }^{6}$ Institute and Clinic for Occupational, Social and Environmental Medicine, University Hospital, LMU Munich, Munich, Germany.

Received: 26 October 2020 Accepted: 29 July 2021

Published online: 25 August 2021

\section{References}

1. European Chemicals Agency (ECHA). Bisphenol A. https://echa.europa.eu/ hot-topics/bisphenol-a (last accessed June $26^{\text {th }}, 2020$ ).

2. Geens T, Aerts D, Berthot C, Bourguignon J-P, Goeyens L, Lecomte $P$, et al. A review of dietary and non-dietary exposure to bisphenol-a. Food Chem Toxicol. 2012:50(10):3725-40. https://doi.org/10.1016/j.fct.2012.07.059.

3. Völkel W, Colnot T, Csanády GA, Filser JG, Dekant W. Metabolism and kinetics of bisphenol a in humans at low doses following Oral administration. Chem Res Toxicol. 2002;15(10):1281-7. https://doi.org/10.1 021/tx025548t.

4. European Food Safety Authority (EFSA). Bisphenol A. http://www.efsa. europa.eu/en/topics/topic/bisphenol (last accessed June $26^{\text {th }}, 2020$ ).

5. WHO \& UNEP (2012) State of the Science of Endocrine Disrupting Chemicals. Edited by Ake Bergman, Jerrold J. Heindel, Susan Jobling, Karen A. Kidd and R. Thomas Zoeller. Summary for Decision-Makers. https://apps. who.int/iris/bitstream/handle/10665/78102/WHO_HSE_PHE_IHE_2013.1_eng. pdf; jsessionid $=23 A A 7 C 68664$ A579E3E783C2CB20270B5? sequence $=1$ (last accessed $26^{\text {th }}$ June, 2020) 
6. Rochester JR. Bisphenol a and human health: a review of the literature. Reprod Toxicol. 2013;42:132-55. https://doi.org/10.1016/j.reprotox.2013.08. 008.

7. Bellinger DC. Prenatal exposures to environmental chemicals and children's neurodevelopment: an update. Saf Health Work. 2013;4(1):1-11. https://doi. org/10.5491/SHAW.2013.4.1.1.

8. Ejaredar M, Lee Y, Roberts DJ, Sauve R, Dewey D. Bisphenol a exposure and children's behavior: a systematic review. Journal of Exposure Science and Environmental Epidemiology. 2016:1-9.

9. Mustieles V, Messerlian C, Reina I, Rodríguez-Carrillo A, Olea N, Fernández MF. Is bisphenol a (BPA) a threat to Children's behavior? J Mental Health \& Clin Psychology. 2018;2(1):6-9.

10. Vrijheid M, Casas M, Gascón M, Valvi D, Nieuwenhuijsen M. Environmental pollutants and child health - a review of recent concerns. Int J Hig Environ Health. 2016;219(4-5):331-42. https://doi.org/10.1016/j.ijheh.2016.05.001.

11. Mustieles V, Fernández MF. Bisphenol a shapes children's brain and behavior: towards an integrated neurotoxicity assessment including human data. Environ Health. 2020;19(1):66. https://doi.org/10.1186/s12940-020-0062 $0-\mathrm{y}$.

12. Polanczyk GV, Salum GA, Sugaya LS, Caye A, Rohde LA. Annual research review: a meta-analysis of the worldwide prevalence of mental disorders in children and adolescents. J Child Psychol Psychiatry. 2015;56(3):345-65. https://doi.org/10.1111/jcpp.12381.

13. Choi J, Knudsen LE, Mizrak S, Joan A (2017) Identification of exposure to environmental Chemicals in Children and Older Adults Using Human Biomonitoring Data Sorted by age: results from a literature review. Int J Hyg environ health 220(2 Pt a): 282-298.

14. Schindler BK, Esteban M, Koch HM, Castano A, Koslitz S, Cañas A, et al. The European COPHES/DEMOCOPHES project: towards transnational comparability and reliability of human biomonitoring results. Int J Hyg Environ Health. 2014;217(6):653-61. https://doi.org/10.1016/j.jiheh.2013.12. 002.

15. Koppen G, Govarts E, Vanermen G, Voorspoels S, Govindan M, Dewolf MC, et al. Mothers and children are related, even in exposure to chemicals present in common consumer products. Environ Res. 2019;175:297-307. https://doi.org/10.1016/j.envres.2019.05.023.

16. Covaci A, Den Hond E, Geens T, Govarts E, Koppen G, Frederiksen H, et al. Urinary BPA measurements in children and mothers from six European states: overall results and determinants of exposure. Environ Res. 2015;141: 77-85. https://doi.org/10.1016/j.envres.2014.08.008.

17. EFSA CEF Panel (2015) Scientific opinion on the risks to public health related to the presence of bisphenol a (BPA) in foodstuffs: executive summary. EFSA J 13(1): 3978, 23pp, DOl: https://doi.org/10.2903/j.efsa.2015.3 978.

18. Louro H, Heinälä M, Bessems J, Buekers J, Vermeire T, Woutersen $M$, et al. Human biomonitoring in health risk assessment in Europe: current practices and recommendations for the future. Int J Hyg Environ Health. 2019;222(5): 727-37. https://doi.org/10.1016/j.ijheh.2019.05.009.

19. Kiedic M, Kubica S, Chrusciel A, Hreczuch W. Next generation of polish technology to obtain bisphenol a - ADVANCE BPA process. CHEMIX. 2013; 67(11):1097-104

20. Konieczna A, Rutkowska A, Rachon D. Health risks of exposure to bisphenol a (BPA). Rocz Panstw Zakl Hig. 2015;66(1):5-11.

21. Polańska K, Hanke W, Król A, Potocka A, Waszkowska M, Jacukowicz A, et al. Polish mother and child cohort study (REPRO_PL) - methodology of the follow-up of the children at the age of 7. Int J Occup Med Environ Health. 2016;29(6):883-93. https://doi.org/10.13075/ijomeh.1896.00811.

22. Jankowska A, Polańska K, Koch HM, Pälmke C, Waszkowska M, Stańczak A, Wesołowska E, Hanke W, Bose-O'Reilly S, Calamandrei G, Garí M (2019) Phthalate exposure and neurodevelopmental outcomes in early school age children from Poland. Environ res 179(Pt B): 108829.

23. Polańska K, Hanke W, Gromadzińska J, Ligocka D, Gulczyńska E, Sobala W, et al. Polish mother and child cohort study - defining the problem, the aim of the study and methodological assumption. Int J Occup Med Environ Health. 2009;22(4):383-91. https://doi.org/10.2478/v10001-009-0037-0.

24. Polańska K, Hanke W, Jurewicz J, Sobala W, Madsen C, Nafstad P, et al. Polish mother and child cohort study (REPRO_PL) - methodology of followup of the children. Int J Occup Med Environ Health. 2011:24(4):391-8. https://doi.org/10.2478/s13382-011-0026-y.

25. Garí M, Koch HM, Pälmke C, Jankowska A, Wesolowska E, Hanke W, et al. Determinants of phthalate exposure and risk assessment in children from
Poland. Environ Int. 2019;127:742-53. https://doi.org/10.1016/j.envint.2019. 04.011.

26. Calafat AM, Koch HM, additional coauthors (2020) BPA and risk assessment. Lancet Diabetes Endocrinol 8(4): 269-270, DOI: https://doi.org/10.1016/ S2213-8587(20)30070-X.

27. Koch HM, Kolossa-Gehring M, Schröter-Kermani C, Angerer J, Brüning T. Bisphenol a in $24 \mathrm{~h}$ urine and plasma samples of the German environmental specimen Bank from 1995 to 2009: a retrospective exposure evaluation. J Expo Sci Environ Epidemiol. 2012;22(6):610-6. https://doi.org/1 $0.1038 /$ jes.2012.39

28. Kasper-Sonnenberg $M$, Wittsiepe J, Koch HM, Fromme H, Wilhelm M. Determination of bisphenol a in urine from mother-child pairs - results from the Duisburg birth cohort study, Germany. J Toxicol Environ Health A. 2012;75(8-10):429-37. https://doi.org/10.1080/15287394.2012.674907.

29. Larsen K. Creatinine assay by a reaction-kinetic principle. Clin Chim Acta. 1972;41:209-17. https://doi.org/10.1016/0009-8981(72)90513-X.

30. Stragierowicz J, Mikołajewska K, Zawadzka-Stolarz M, Polańska K, Ligocka D (2013) Estimation of cutoff values of cotinine in urine and saliva for pregnant women in Poland Biomed Res Int 386784.

31. Lupsa IR, Nunes B, Ligocka D, Gurzau AE, Jakubowski M, Casteleyn L, et al. Urinary cotinine levels and environmental tobacco smoke in mothers and children of Romania, Portugal and Poland within the European human biomonitoring pilot study. Environ Res. 2015;141:106-17. https://doi.org/10.1 016/j.envres.2015.03.018.

32. Kulaga Z, Rózdzynska-Swiatkowska A, Grajda A, Gurzkowska B, Wojtylo M, Gózdz M, et al. Percentile charts for growth and nutritional status assessment in polish children and adolescents from birth to 18 years of age. Standardy Medyczne / Pediatria. 2015;12:119-35.

33. Polańska K, Krol A, Kaluzny P, Ligocka D, Mikolajewska K, Shaheen S, et al. Estimation of saliva cotinine cut-off points for active and passive smoking during pregnancy-polish mother and child cohort (REPRO_PL). Int J Environ Res Public Health. 2016;13(12):E1216.

34. Goodman R, Scott S. Child psychiatry: Wiley; 1997.

35. Mazur J, Tabak I, Kololo H. Towards a better assessment of child and adolescent mental health status. Polish version of strengths and difficulties questionnaire. Med Wieku Rozwoj. 2007;11(1):13-24.

36. Duinhof EL, Lek KM, de Looze ME, Cosma A, Mazur J, Gobina I, et al. Revising the self-report strengths and difficulties questionnaire for crosscountry comparisons of adolescent mental health problems: the SDQ-R. Epidemiol Psychiatr Sci. 2019;29:e35.

37. Grob A, Meyer ChS, Hagmann-von Arx P (2009) IDS intelligence and development scales - children aged 5-10.

38. Koch HM, Wittassek M, Brüning T, Angerer J, Heudorf U. Exposure to phthalates in 5-6 years old primary school starters in Germany - a human biomonitoring study and cumulative risk assessment. Int J Hyg Environ Health. 2011;214(3):188-95. https://doi.org/10.1016/j.ijheh.2011.01.009.

39. Remer T, Neubert A, Maser-Gluth C. Anthropometry-based reference values for 24-h urinary creatinine excretion during growth and their use in endocrine and nutritional research. Am J Clin Nutr. 2002;75(3):561-9. https:// doi.org/10.1093/ajcn/75.3.561.

40. Core Team R. R: a language and environment for statistical computing. Vienna: R Foundation for Statistical Computing; 2021. https://www.R-project. org/

41. Wickham H. ggplot2: elegant graphics for data analysis. New York URL. http://ggplot2.org: Springer-Verlag; 2016. https://doi.org/10.1007/978-3-31 9-24277-4.

42. Gelman A. Scaling regression inputs by dividing by two standard deviations. Stat Med. 2008;27(15):2865-73. https://doi.org/10.1002/sim.3107.

43. Kasper-Sonnenberg M, Koch HM, Wittsiepe J, Brüning T, Wilhelm M. Phthalate metabolites and bisphenol a in urines from German school-aged children: results of the Duisburg birth cohort and Bochum cohort studies. Int J Hyg Environ Health. 2014;217(8):830-8. https://doi.org/10.1016/j.ijheh.2 014.06.001.

44. Correia-Sá L, Kasper-Sonnenberg M, Schütze A, Pälmke C, Norberto S, Calhau $C$, et al. Exposure assessment to bisphenol a (BPA) in Portuguese children by human biomonitoring. Environ Sci Pollut Res. 2017:24(35): 27502-14. https://doi.org/10.1007/s11356-017-0358-7.

45. Frederiksen $\mathrm{H}$, Nielsen JK, Morck TA, Hansen PW, Jensen JF, Nielsen O, et al. Urinary excretion of phthalate metabolites, phenols and parabens in rural and urban Danish mother-child pairs. Int J Hyg Environ Health. 2013;216(6): 772-83. https://doi.org/10.1016/j.jiheh.2013.02.006. 
46. Sakhi AK, Sabaredzovic AS, Papadopoulou E, Cequier E, Thomsen C. Levels, variability and determinants of environmental phenols in pars of Norwegian mothers and children. Environ Int. 2018;114:242-51. https://doi.org/10.1016/ j.envint.2018.02.037.

47. Snoj Tratnik J, Kosjek T, Heath E, Mazej D, Ćehić S, Karakitsios SP, et al. Urinary bisphenol a in children, mothers and fathers from Slovenia: overall results and determinants of exposure. Environ Res. 2019;168:32-40. https:// doi.org/10.1016/j.envres.2018.09.004.

48. Çok I, Ikidag ÖT, Battal D, Aktas A. Assessment of bisphenol a levels in preschool children: results of a human biomonitoring study in Ankara Turkey. J Clin Res Pediatr Endocrinol. 2020;12(1):86-94. https://doi.org/10.42 74/jcrpe.galenos.2019.2019.0087.

49. NHANES (2019) Fourth National Report on human exposure to environmental chemicals. Updated tables, volume 1. CDC.

50. Stacy SL, Papandonatos GD, Calafat AM, Chen A, Yolton K, Lanphear BP, et al. Early life bisphenol a exposure and neurobehavior at 8 years of age: identifying windows of heightened vulnerability. Environ Int. 2017;107:25865. https://doi.org/10.1016/j.envint.2017.07.021.

51. Grohs MN, Reynolds JE, Liu J, Martin JW, Pollock T, Lebel C, et al. Prenatal maternal and childhood bisphenol a exposure and brain structure and behavior of young children. Environ Health. 2019;18(1):85. https://doi.org/1 0.1186/s12940-019-0528-9.

52. Rocha BA, Asimakopoulos AG, Honda M, da Costa NL, Barbosa RM, Barbosa F Jr, et al. Advanced data mining approaches in the assessment of urinary concentrations of bisphenols, chlorophenols, parabens and benzophenones in Brazilian children and their associations to DNA damage. Environ Int. 2018;116:269-77. https://doi. org/10.1016/j.envint.2018.04.023.

53. Guo J, Zhang J, Wu C, Xiao H, Lv S, Lu D, et al. Urinary bisphenol a concentrations and adiposity measures at age 7 years in a prospective birth cohort. Chemosphere. 2020;251:126340. https://doi.org/10.1016/j. chemosphere.2020.126340.

54. Li N, Ho W, Sun Wu RS, Ying GG, Wang Z, Jones K, et al. Organophosphate flame retardants and bisphenol a in children's urine in Hong Kong: has the burden been underestimated? Ecotoxicol Environ Saf. 2019;183:109502. https://doi.org/10.1016/j.ecoenv.2019.109502.

55. Lee S, Lee HA, Park B, Han H, Park BH, Oh SY, et al. A prospective cohort study of the association between bisphenol a exposure and the serum levels of liver enzymes in children. Environ Res. 2018;161:195-201. https:// doi.org/10.1016/j.envres.2017.11.007.

56. Xue J, Wu Q, Sakthivel S, Pavithran PV, Vasukutty JR, Kannan K. Urinary levels of endocrine-disrupting chemicals, including bisphenols, bisphenol a diglycidyl ethers, benzophenones, parabens, and triclosan in obese and non-obese Indian children. Environ Res. 2015;137:120-8. https://doi.org/10.1 016/j.envres.2014.12.007

57. Stacy LS, Eliot M, Calafat AM, Chen A, Lanphear BP, Hauser R, et al. Patterns, variability, and predictors of urinary bisphenol a concentrations during childhood. Environ Sci Technol. 2016;50(11):5981-90. https://doi.org/10.1 021/acs.est.6b00794

58. Huang RP, Liu ZH, Yin H, Dang Z, Wu PX, Zhu NW, et al. Bisphenol a concentrations in human urine, human intakes across six continents, and annual trends of average intakes in adult and child populations worldwide: a thorough literature review. Sci Total Environ. 2018;626:971-81. https://doi. org/10.1016/j.scitotenv.2018.01.144.

59. Frederiksen $H$, Nielsen $O$, Koch HM, Skakkebaek NE, Juul A, Jørgensen $N$, et al. Changes in urinary excretion of phthalates, phthalate substitutes, bisphenols and other polychorinated and phenolic substances in young Danish men; 2009-2017. Int J Hyg Environ Health. 2020;223(1):93-105. https://doi.org/10.1016/j.ijheh.2019.10.002.

60. LaKind JS, Naiman DQ. Temporal trends in bisphenol a exposure in the United States from 2003-2012 and factors associated with BPA exposure: spot samples and urine dilution complicate data interpretation. Environ Res 2015;142:84-95. https://doi.org/10.1016/j.envres.2015.06.013.

61. LaKind JS, Pollock T, Naiman DQ, Kim S, Nagasawa A, Clarke J. Factors affecting interpretation of national biomonitoring data from multiple countries: BPA as a case study. Environ Res. 2019;173:318-29. https://doi. org/10.1016/j.envres.2019.03.047.

62. Huang RP, Liu ZH, Yuan SF, Yin H, Dang Z, Wu PX. Worldwide human daily intakes of bisphenol a (BPA) estimated from global urinary concentration data (2000-2016) and its risk analysis. Environ Pollut. 2017;230:143-52. https://doi.org/10.1016/j.envpol.2017.06.026.
63. Montazeri P, Thomsen C, Casas M, de Bont J, Haug LS, Maitre L, et al. Socioeconomic position and exposure to multiple environmental chemical contaminants in six European mother-child cohorts. Int J Hyg Environ Health. 2019;222(5):864-72. https://doi.org/10.1016/j.ijheh.2019.04.002.

64. Dunder L, Lejonklou MH, Lind PM, Lind L. Urinary bisphenol a and serum lipids: a meta-analysis of six NHANES examination cycles (2003-2014). J Epidemiol Community Health. 2019;73(11):1012-9. https://doi.org/10.1136/ jech-2019-212555.

65. Braun JM, Kalkbrenner AE, Calafat AM, Yolton $\mathrm{K}$, Ye X, Dietrich KN, et al. Impact of early-life bisphenol a exposure on behavior and executive function in children. Pediatrics. 2011;128(5):873-82. https://doi.org/10.1542/ peds.2011-1335

66. Harley KG, Gunier RB, Kogut K, Johnson C, Bradman A, Calafat AM, et al. Prenatal and early childhood bisphenol a concentrations and behavior in school-aged children. Environ Res. 2013;126:43-50. https://doi.org/10.1016/j. envres.2013.06.004.

67. Roen EL, Wang Y, Calafat AM, Wang S, Margolis A, Herbstman J, et al. Bisphenol a exposure and behavioral problems among inner city children at 7-9 years of age. Environ Res. 2015;142:739-45. https://doi.org/10.1016/j. envres.2015.01.014.

68. Hong S-B, Hong Y-C, Kim J-W, Park E-J, Shin M-S, Kim B-N, et al. Bisphenol a in relation to behavior and learning of school-age children. J Child Psychol Psychiatry. 2013;54(8):890-9. https://doi.org/10.1111/jcpp.12050.

69. Perera F, Nolte ELR, Wang Y, Margolis AE, Calafat AM, Wang S, et al. Bisphenol a exposure and symptoms of anxiety and depression among inner city children at 10-12 years of age. Environ Res. 2016;151:195-202. https://doi.org/10.1016/j.envres.2016.07.028.

70. Perez-Lobato R, Mustieles V, Calvente I, Jimenez-Diaz I, Ramos R, CaballeroCasero $\mathrm{N}$, et al. Exposure to bisphenol a and behavior in school-age children. Neurotoxicology. 2016;53:12-9. https://doi.org/10.1016/j.neuro.201 5.12.001.

71. Jedynak P, Maitre L, Guxens M, Gützkow KB, Julvez J, López-Vicente M, et al. Prenatal exposure to a wide range of environmental chemicals and child behaviour between 3 and 7 years of age - an exposome-based approach in 5 European cohorts. Sci Total Environ. 2021;763:144115. https://doi.org/10.1 016/j.scitotenv.2020.144115.

72. Maitre L, Julvez J, López-Vicente M, Warembourg C, Tamayo-Uria I, Philippat C, et al. Early-life environmental exposure determinants of child behavior in Europe: a longitudinal, population-based study. Environ Int. 2021;153: 106523. https://doi.org/10.1016/j.envint.2021.106523.

73. Jaworowska A, Matczak A, Fecenec D (2012) Skale Inteligencje I Rozwoju Dzieci W Wieku 5-10 Lat. Podrecznik. Pracownia Testów Psychologicznych Polskiego Towarzystwa Psychologicznego. Manual. Laboratory of Psychological Tests of the polish psychological association, Warsaw Warszawa. [scales of intelligence and development - children aged 5-10].

74. Calafat AM, Longnecker MP, Koch HM, Swan SH, Hauser R, Goldman LR, et al. Optimal exposure biomarkers for nonpersistent Chemicals in Environmental Epidemiology. Environ Health Perspect. 2015;123(7):A166-8. https://doi.org/10.1289/ehp.1510041.

\section{Publisher's Note}

Springer Nature remains neutral with regard to jurisdictional claims in published maps and institutional affiliations.

Ready to submit your research? Choose BMC and benefit from:

- fast, convenient online submission

- thorough peer review by experienced researchers in your field

- rapid publication on acceptance

- support for research data, including large and complex data types

- gold Open Access which fosters wider collaboration and increased citations

- maximum visibility for your research: over $100 \mathrm{M}$ website views per year

At $\mathrm{BMC}$, research is always in progress.

Learn more biomedcentral.com/submissions 